\title{
A ALFABETIZAĈ̣̃O E SUA RELAC̣ÃO COM O USO DO COMPUTADOR: 0 SUPORTE DIGITAL COMO MAIS UM INSTRUMENTO DE ENSINO-APRENDIZAGEM DA ESCRITA
}

\author{
Julianna Silva Glória" \\ Universidade Vale do Rio Doce (UNIVALE) \\ Isabel Cristina Alves da Silva Frade** \\ Universidade Federal de Minas Gerais (UFMG)
}

RESUMO: Neste artigo apresentamos dados de pesquisa desenvolvida no programa de Pós-Graduação da FAE/UFMG em que tratamos sobre as implicações de se introduzir o computador como suporte de escrita na fase de alfabetização. Entre as referências estão os estudos sobre os letramentos, como aqueles produzidos por Magda Soares e Brian Street, e sobre a história da leitura e do livro e a história da cultura escrita.Na metodologia adotamos os princípios da pesquisa qualitativa, com proposta de intervenção colaborativa, com a proposição de acompanhar crianças de 6 anos em laboratório de informática de escola pública em Belo Horizonte, Minas Gerais, durante o ano de 2009, em várias situações de atividades de escritura e leitura na tela do computador, tanto na utilização de programas, atividades, jogos, como em atividades com gêneros da esfera digital.

Palavras-chave: Letramento digital. Alfabetização. Cultura digital. Suportes e instrumentos de escrita.

"http://dx.doi.org/10.1590/0102-4698127905

"Doutora em Educação pela Universidade Federal de Minas Gerais (UFMG). Professora de Ensino Superior e Coordenadora do Curso de Letras da Universidade Vale do Rio Doce. E-mail: juliannasilvagloria@yahoo.com.br. "* Professora da Faculdade de Educação da Universidade Federal de Minas Gerais (FaE/UFMG ), pesquisadora do Centro de Alfabetização, Leitura e Escrita (Ceale/FAE/UFMG) ). Doutora em Educação, pós-doutora pela FE/USP/Brasil e Institut National de Recherche Pédagogique/França (2006/2007) e pela UDESC/SC (2011/2012). E-mail: icrisfrade@gmail.com 
LITERACY AND ITS RELATION WITH COMPUTER USE: THE DIGITAL SUPPORT AS ANOTHER INSTRUMENT TO TEACH AND LEARN HOW TO WRITE

ABSTRACT: This paper presents research data developed by the Graduate program FAE / UFMG. We treat the implications of introducing the computer as a writing support in literacy phase. Among the references are studies about literacy, such as those produced by Magda Soares (1998), Brian Street (2009), about the history of reading and the book (Chartier, 1997) and history of written culture (Gómez, 2003). Methodologically, we have adopted the principles of qualitative research, including proposals for collaborative intervention. We accompanied 6 years old children in public school computer labs in Belo Horizonte, Minas Gerais, during the year 2009 in various writing and reading on a computer screen situations and the use of programs, games, and activities with digital sphere genres.

Keywords: Digital literacy. Literacy. Digital culture.Supports and writing instruments.

\section{INTRODUĈ̣̃O}

Vários são os instrumentos e os suportes utilizados pela escola, ao longo da história, para incentivar as crianças a aprenderem a ler e a escrever textos (FRADE, 2009, p. 61), como pena de ganso, pluma metálica, lápis, lousa, cadernos, folhas soltas, quadro-negro, borracha, entre outros. Esses suportes, que fazem parte das práticas sociais internas e externas à escola, podem alterar o modo como se aprende e como se tomam as decisões em torno do ensino da leitura e da escrita (CHARTIER, 2007; FRADE, 2009). Entre essas práticas podemos incluir, atualmente, o uso do computador como suporte de texto e como modo de inscrição da escrita.

Apresentamos, neste artigo, uma reflexão sobre as implicações de se introduzir tal suporte na fase de alfabetização, supondo que a compreensão do computador como um suporte multimodal de texto que oferece imagem, som, comunicação on-line, entre outros signos, aguce a percepção das crianças sobre a escrita alfabética. Inspirados nos estudos de Street (2009), afirmamos que os estudos sobre novos letramentos e multimodalidade devem ser articulados para que possamos compreender as diferentes nuances e processos sociais, comunicativos e cognitivos envolvidos em práticas, textos, contextos, espaço e tempo da escrita.

$\mathrm{Na}$ pesquisa utilizamos como referência os estudos sobre os letramentos, como aqueles produzidos por Magda Soares (2002), Brian Street (2009), sobre a história da leitura e do livro (CHARTIER, 1997) 
e a história da cultura escrita (GÓMEZ, 2003). Buscando uma relação entre suportes/instrumentos e a pedagogia da alfabetização, trabalhamos com pesquisas de Anne-Marie Chartier (2008) e Isabel Frade (2006). O trabalho de Molinari e Emília Ferreiro (2007), que relaciona aquisição da escrita e uso de novos suportes, também serviu de contraponto. No tocante à análise da produção de gêneros textuais típicos do mundo digital, utilizamo-nos dos trabalhos de Marchuschi (2009).

Do ponto de vista metodológico, adotamos os princípios da pesquisa qualitativa, com proposta de intervenção colaborativa, com a proposição de acompanhar crianças de 6 anos em laboratório de informática de escola pública em Belo Horizonte, Minas Gerais, durante o ano de 2009, em várias situações de atividades de escritura e leitura na tela do computador. A pesquisa usou procedimentos de observação, anotação, filmagem e entrevistas. Em relação aos registros, buscando manter um procedimento ético em relação aos sujeitos participantes da pesquisa, codificamos os nomes de nossos colaboradores.

Nosso objetivo mais amplo foi o de responder à seguinte questão: o que ocorre com as crianças em processo inicial de aquisição da escrita e de alguns de seus gêneros quando utilizam, no mesmo período, o computador? Neste texto buscamos explorar o potencial do computador como mais um instrumento de alfabetização, entre tantos outros já utilizados e conhecidos pela escola, colocando em evidência indícios sobre aspectos cognitivos e físicos relacionados ao ato de escrever e ler no novo suporte. Utilizando-nos da produção escrita, da reflexão sobre interações e de dados fornecidos pelas crianças em entrevistas, analisamos as atividades de teclar, copiar, colorir e produzir e-mails e cartões, visando demonstrar o que ocorre com as crianças no momento dessas diferentes produções desenvolvidas no computador.

\section{POR QUE TECLAR É DIFERENTE NA FASE DE ALFABETIZAC̣ÃO?}

Analisaremos neste tópico uma ação própria do computador que traz implicações diretas para a experimentação da escrita por parte dos sujeitos de nossa investigação. Faremos nossa reflexão a partir de dados de entrevistas ocorridas em aulas diferentes, nas quais os alunos ${ }^{1}$ experimentaram atividades distintas. O diálogo abaixo ocorreu após aula de digitação do alfabeto.

Pesquisadora: Aluno TA você gostou da aula de fazer o alfabeto?

Aluno TA: Gostei.

Educação em Revista | Belo Horizonte | v.31 |n.03 | p. 339-358 | Julho-Setembro 2015 
Pesquisadora: E qual a diferença entre fazer o alfabeto no caderno e no computador? Aluno TA: É que no computador eu tenho que apertar a tecla e no caderno eu tenho que escrever; é legal!

Pesquisadora: O que é legal?

Aluno TA: Apertar a tecla e escrever.

Pesquisadora: Você acha que aprende com os dois?

Aluno TA: Eu acho que aprendo mais no computador.

Pesquisadora: Por quê?

Aluno TA: Porque no computador a gente aprende muita coisa e tem que estudar muito.

Pesquisadora: E você, GM, já tinha feito o alfabeto no computador?

Aluna GM: Não.

Pesquisadora: E o que você achou?

Aluna GM: Foi legal!

Pesquisadora: E você gosta de fazer o alfabeto no caderno?

Aluna GM: É legal também; só que no caderno a gente usa o lápis e no computador o teclado.

Pesquisadora: $\mathrm{O}$ que você achou do teclado?

Aluna GM: É mais difícil um pouco para mim porque faz "AAAAAAAAAAA AAAA" às vezes e eu levo um susto. [risada] Depois eu aprendi a apertar menos a tecla e aí levei menos susto. [risada]

O ato de teclar é muito diferente se comparado ao ato de escrever de forma manuscrita; é uma ação que compõe a multimodalidade, que é bem potencializada no texto digital. ${ }^{2}$ Quando se trata de crianças em período de alfabetização inicial, isso ganha um realce maior ainda se levarmos em consideração que gestos motores são complexos nessa fase. Portanto, muitas vezes teclar parece ser um gesto mais "tranquilo" de se realizar, mesmo quando, a princípio, a criança precisa se acostumar com a intensidade do toque, conforme comentário de GM.

Embora o aprendizado da própria intensidade envolva habilidades motoras específicas que uma criança pequena ainda não domina, apertar uma tecla pode ser muito mais suave do que fazer com o lápis gestos motores para efetuar o registro da letra, embora o uso concomitante do mouse represente uma outra habilidade, que precisa ser melhor investigada. Ou seja, ter de diminuir a intensidade do toque, sem dúvida, pode ser mais fácil ou menos doloroso do que aprender a fazer gestos motores que, além da intensidade do toque - também envolvida no uso de instrumentos como lápis e papel -, supõem o domínio do traçado para que a letra se concretize na folha. O segundo trecho de entrevista que complementa nossa análise ocorreu após aula 
em que os alunos coloriram a letra do próprio nome e digitaram o nome na tela do computador. $\mathrm{O}$ aluno $\mathrm{RO}$ faz a seguinte declaração:

Pesquisadora: E o que você mais gostou de fazer: digitar ou desenhar?

Aluno RO: Digitar o texto.

Pesquisadora: Por quê?

Aluno RO: Porque não gosto de desenhar.

Pesquisadora: Nem no computador?

Aluno RO: No computador eu gosto mais.

Pesquisadora: Qual a diferença de colorir e desenhar na folha do caderno e no computador?

Aluno RO: É que no computador a minha mão não dói.

Escrever sem doer. Esse parece ser, na perspectiva dos sujeitos da pesquisa, um dos benefícios que o suporte digital de texto traz para a criança em fase de alfabetização. Apesar das evidências mostradas nos diálogos, não estamos compreendendo que a escrita manuscrita não deva mais ser realizada. Ressaltamos que ela permanece nas práticas culturais, e aprender a escrever à mão sempre será uma habilidade importante. Fazendo um paralelo com as práticas de leitura, não nos esqueçamos do alerta de Chartier (2002, p. 117), que indica que "o surgimento da escrita cibernética não significa o fim do livro ou do leitor”.

Queremos, na verdade, ressaltar a necessidade de a escola proporcionar aos alunos mais atividades de alfabetização no computador, porque esse uso concomitante a outras práticas de escrita pode ser interessante para o amadurecimento dos gestos motores da criança. Além disso, pode liberá-la para se concentrar nos aspectos construtivos de sua escrita, em vez de se perder na ação cognitiva ao se incomodar com a dor na mão.

\section{EXERCÍCIO DE CÓPIA DIGITAL: MAIS UMA FORMA DE CÓPIA INTELIGENTE}

Muito já se discutiu sobre o uso de cópia na fase de alfabetização, e, para alguns, essa seria uma atividade pouco significativa na escola, visto que os alunos a realizam de forma mecânica, sem pensar na construção das sílabas, das palavras e do texto. Entretanto, Delia Lerner (2008) e Anne-Marie Chartier (2008), ao serem indagadas sobre o papel da cópia manuscrita, apresentam-na como uma atividade de aprendizagem em que o aluno pode internalizar vários conhecimentos sobre a escrita e a construção do texto.

Em nossa pesquisa, tivemos a oportunidade de acompanhar atividades de cópia que os alunos realizaram no computador por meio do 
programa Kolorpaint, do sistema operacional Linux. As atividades foram sugeridas pela professora da turma. A princípio, quando planejamos as aulas, tivemos receio de que essas atividades não fossem tão produtivas, mas aceitamos a proposta da professora $\mathrm{F}^{3}$ como forma de incentivá-la a participar da elaboração das tarefas relacionadas à pesquisa.

Ao observarmos, no laboratório de informática, a realização das práticas de cópia de texto com a turma, percebemos que as produzidas no computador contribuíram para que as crianças pusessem em relevo ou pensassem de outra forma alguns aspectos relacionados à pontuação ou à segmentação das palavras ou das frases. Experimentá-las no computador valorizou ainda mais determinados aspectos que analisamos, com o intuito de refletirmos sobre o quanto a cópia digital - e suas especificidades -, assim como a manuscrita, pode ser uma atividade significativa na fase de alfabetização.

A seguir, descrevemos e analisamos trechos de transcrição de diálogo ocorrido durante aula no laboratório de informática quando ocorreram cópias digitais:

$[\ldots]$

Pesquisadora: Pessoal! Deixe-me falar uma coisa para vocês [eles prestam atenção]. Para separar uma palavra da outra é só apertar essa tecla grande [levanto um teclado e aponto a tecla para eles verem].

Aluno JUM: Ah, eu sei! É só apertar essa tecla então!

Pesquisadora: Muito bem!

[Vou passando de dupla em dupla para mostrar a tecla]

Pesquisadora: RB, já sabe, né?

Aluno RB: Eu já sei, a minha mãe me ensinou [esfrega as mãos satisfeito].

Pesquisadora: VI, você ensinou o AR a separar as palavras?

Aluna VI: Não, foi a tia [a professora] que ensinou a gente.

Aluno AR: Professora, a gente não sabe colocar o acento.

Aluna VI: A gente tá procurando e não acha.

Pesquisadora: É porque tem que fazer duas coisinhas: primeiro, você segura essa tecla com a setinha e vai lá na tecla do acento [AR vai fazendo]; depois, você solta ["solta", digo ao AR] e tecla no E.

Aluna VI: Agora tá com acento. Legal! Me deixa fazer de novo?

[VI repete o que AR fez].

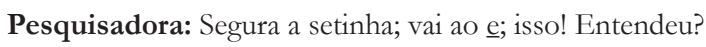

Aluno AR: Juliana, e como faz esse aqui? [AR mostra o til no papel].

Pesquisadora: Aperta o N [AR tecla]; agora vai ao til [AR fala "aqui"; aponta onde está o til; AR vai para as teclas na setinha].

Pesquisadora: Não, AR! Aqui não precisa. É só ir ao til [AR tecla]; agora vai no A. Isso!

Aluno PA: Professora, nós precisamos do ponto de exclamação; só que não dá certo. 
Pesquisadora: Se vocês apertarem só na exclamação não dá certo mesmo; aperta na setinha; segura e tecla na exclamação. [PA faz o gesto] Isso! [ele consegue] Viu?

Aluno DO: Professora, onde eu parei lá; o GB escreveu tudo errado.

Pesquisadora: Vamos lá; primeiro deixe-me ver o que vocês escreveram: "FICAREI COM ELES" [Leio a frase da história].

[Eu aponto na folha onde está o trecho do livro e digo: "você está aqui ó”]

Aluno DO: Apaga pra mim; eu quero apagar.

Pesquisadora: Por quê?

Aluno DO: É que ele escreveu assim ó [gesto em direção à tela] e não vai caber.

Pesquisadora: É só ir pra linha de baixo; tecla aqui ó [aponto para o enter].

[O aluno DO faz o gesto]

Pesquisadora: Isso! Agora continua a escrever, OK?

$[\ldots]$

Analisando a produção dos alunos do ponto de vista dos conceitos que constroem sobre o sistema alfabético da escrita, com apoio nos estudos de Emília Ferreiro e Ana Teberosky (1985) sobre a psicogênese da língua escrita, constatamos que a maioria se encontrava no nível silábico-alfabético, alguns poucos alfabéticos e outros silábicos. Dos que participaram do trecho transcrito acima, AR era silábico; os alunos JUM, PA e DO eram silábico-alfabéticos; somente a aluna VI era alfabética.

Embora pesquisas de Molinari e Ferreiro (2007) tenham constatado que a mudança da escrita de suporte manuscrito para o suporte digital pouco interfere na conceituação sobre o sistema de notação alfabético das crianças, quando distinguimos os suportes digital e manuscrito na nossa pesquisa, verificamos conceituações de outra natureza envolvidas no modo como a escrita se apresenta, além daquela relacionada ao sistema notacional da escrita alfabética. Desse modo, apesar de estarem em níveis de escrita diferentes, no episódio relatado, todos os alunos citados discutem outros elementos gráficos relacionados à escrita: JUM e RB confirmam ou aprendem aspectos relacionados à segmentação entre palavras, AR e VI preocupam-se com a acentuação e o grafismo da palavra (no caso do uso do til), PA está atento à pontuação e DO manifesta suas representações sobre como ocorre a formatação do texto na página virtual.

Assim, independentemente do nível conceitual de escrita, todos pensaram aspectos importantes relacionados ao processo de produção dela. Certamente a atividade de cópia contribuiu para desenvolver a escrita de cada um, aprimorando seus conhecimentos em relação à mesma. Podemos dizer, portanto, que o fato de fazer uma cópia digital acrescenta mais elementos nesse aprendizado. 
A professora $\mathrm{F}$ e nós, ${ }^{4}$ pesquisadores, observamos que, ao escreverem no computador, os alunos se detiveram mais no acento e na pontuação, pelo próprio fato de alguns desses grafismos não serem digitados diretamente, exigindo atenção ao gesto necessário. Assim, pode-se dizer que, ao aprenderem a registrar o acento ou a pontuação, que são aspectos gráficos, usando o teclado do computador, focalizaram mais a atenção nesses aspectos formais.

Segundo a professora $\mathrm{F},{ }^{5}$ foi a partir dessa aula de cópia digitalizada que os alunos começaram, inclusive, a despertar atenção para o uso das letras maiúsculas e minúsculas, isso porque um aspecto gráfico pode levar a uma questão formal ou conceitual da escrita. Assim, logo após a aula de cópia digitalizada, ao realizarem atividades em sala de aula, os alunos passaram a se perguntar se deveriam usar letra maiúscula ou minúscula nos textos em geral. Isso fez com que a professora $\mathrm{F}$ abordasse tal tema de estudo, o que, de acordo com a mesma, foi muito mais construtivo, pois os alunos se mostraram interessados em aprender, visto que era uma questão de uso da escrita para a qual o computador chamara-lhes a atenção. Isso se soma aos aspectos levantados por Anne-Marie Chartier (2008, p. 3) sobre elementos envolvidos no ato de cópia na forma manuscrita, quando afirma que, ao copiar um texto: "O aluno, a uma só vez, adquire novos saberes (quando, por exemplo, copia um resumo de história ou de geografia); assimila as formas sintáticas e lexicais específicas da escrita (quando copia um texto literário, uma poesia); e internaliza a atenção à ortografia".

Ressaltamos que, ao levarmos os alunos, no início do processo de alfabetização, a realizarem um procedimento diferente do que ocorre no texto manuscrito para registrar o acento, contribuímos para que eles observassem com maior focalização algumas marcas gráficas que caracterizam o texto escrito. No computador, anteciparam o acento à letra digitalizada, e não o contrário, como acontece na escrita manuscrita; utilizaram outro tipo de gesto - teclar para fazer a pontuação, a letra maiúscula e a minúscula, entre outros. Assim, devemos estar atentos ao que ocorre quando uma criança copia, para problematizarmos melhor o ato de cópia. Como alerta Delia Lerner (2008, p. 3):

Se reconhecermos que a cópia é somente uma das atividades que contribuem para a aquisição da escrita, se a incluirmos como recurso para resolver problemas de produção, se não esperarmos que o resultado seja cópia fiel do modelo e apreciarmos as diferenças como expressão da atividade intelectual das crianças no processo de reprodução, então podemos dar lugar à cópia no processo de alfabetização.

Da mesma forma como a autora observa a cópia manuscrita, entendemos que a cópia digitalizada acrescenta outros elementos construtivos. A novidade está no fato de que esse tipo de atividade feita no 
computador exige da criança pensar todos os elementos de formalização do registro digital da escrita. Assim, enquanto na cópia manuscrita a criança precisa apenas reproduzir o acento, a pontuação, a letra etc., na cópia digital, a mesma precisa saber, por exemplo, que para registrar a letra maiúscula deve apertar a tecla "caps lock" antes de teclar a letra.

Portanto, a criança é estimulada a fazer algumas antecipações, além do que aprende pelo registro em si da escrita (situação similar ocorre no texto manuscrito), porque precisa aprender um procedimento prévio necessário para que esse registro aconteça. Acreditamos que o acréscimo de novos fatores materiais na forma de registrar a escrita potencializa o computador como instrumento importante de alfabetização e que traz implicações no modo de pensar, causando interferências na escrita daqueles que se encontram em processo de aquisição da escrita.

\section{CULTURA DIGITAL AOS 6 ANOS}

Como apresentado, acompanhamos uma turma que se apropriava do sistema alfabético e que teve condição de usufruir, simultaneamente ao processo de apropriação da escrita, de um contato com a cultura digital em aulas de produção e de leitura de texto ministradas em laboratório de informática.

Para a maioria dos alunos, essas aulas no laboratório de informática da escola representaram o primeiro contato pessoal ${ }^{6}$ com o manuseio de determinados instrumentos da cultura digital ${ }^{7}$, e, mesmo para os que tinham o computador em casa e o utilizavam para jogos de entretenimento, essa foi a oportunidade de conhecer os programas por meio dos quais poderia se comunicar por meio da escrita, mesmo considerando que alguns alunos relataram ficar observando o pai e a mãe usarem a internet para se comunicar via e-mail ou $\mathrm{Orkut}^{8}$, o que classificamos como contato indireto com o texto que circula em meios digitais.

Sabemos que esses sujeitos de nossa pesquisa, de alguma forma (direta ou indiretamente), dentro e fora da escola, têm a oportunidade de conviver com diversos materiais escritos em variados suportes. Mesmo aqueles alunos cujos pais são menos escolarizados ou têm menos condições financeiras de comprar um livro, computador ou até mesmo um jornal, quando vão ao comércio com familiares, têm a chance de observar o uso do computador nas lojas ou nos bancos, têm acesso a jornais mais populares e a projetos de distribuição gratuita de literatura à população. 
A seguir, apresentamos o trabalho realizado por um aluno na aula em que todos tiveram que colorir a letra inicial do nome e digitar o próprio nome no espaço virtual, o que se caracterizou como um trabalho multimodal. Os alunos receberam o desenho pronto da letra acompanhado da ilustração de um animal com a inicial do nome da criança em maiúscula/minúscula; abaixo do desenho desse animal aparecia a escrita da palavra que representava o nome do animal. Veja trabalho feito pelo aluno TA:

FIGURA 1 - Atividade do aluno TA

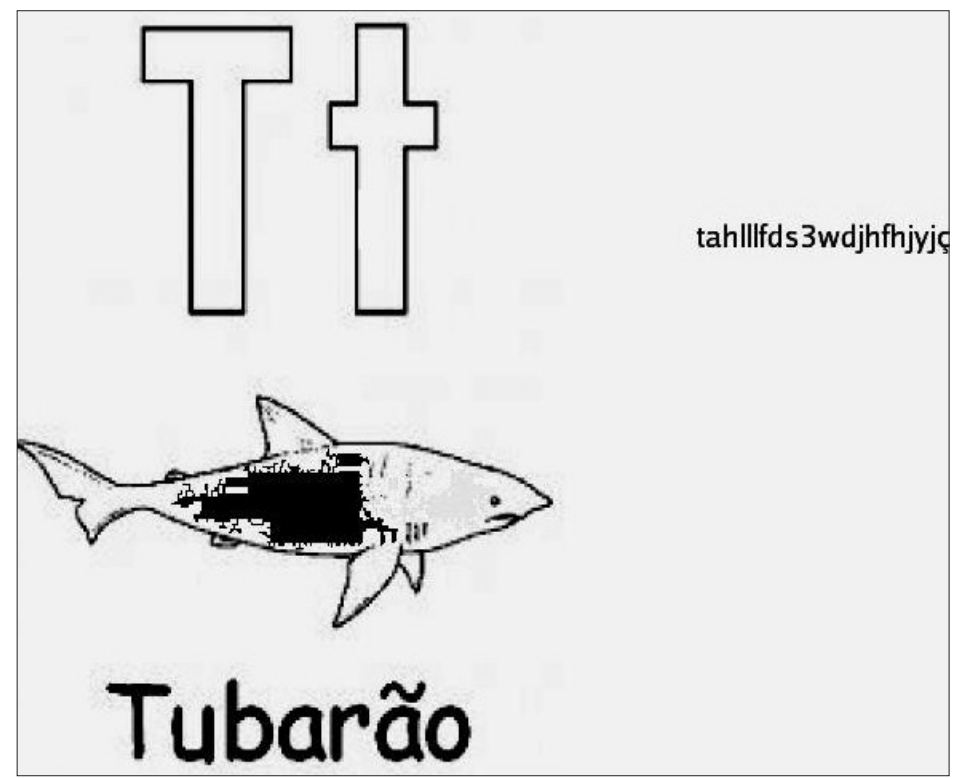

Fonte: BLOG DA TURMA, 2009.

Como se pode perceber com base no colorido feito pelo aluno citado, o mesmo ainda não tinha muito domínio das ferramentas para colorir. No dia em que fez essa atividade, tentou usar o baldinho, ${ }^{9}$ mas não conseguiu, porque o programa estava dando erro. Chegamos a chamar a professora $\mathrm{D}^{10}$ para ajudar a resolver, mas ela não conseguiu sanar o problema técnico

Observamos que, ao iniciar a atividade, o aluno foi direto nessa ferramenta, por tê-la usado nas aulas anteriores e por saber que, para colorir, com o baldinho o procedimento seria supostamente mais fácil: bastava clicar no baldinho, na cor desejada e no espaço a ser colorido que tudo ficaria pronto instantaneamente. Em relação às outras ferramentas (spray e pincel), essas exigem mais do sujeito que 
ainda não tem muita habilidade, pois é preciso clicar e arrastar para colorir. Os efeitos desse tipo de aprendizado são muitos; afinal, não é só usar uma ferramenta de um programa de computador. A partir desse aprendizado os alunos adquirem competência para lidar com outros modos de inscrição e registro da escrita no contexto da cultura digital presentes em nossa sociedade.

Além de trabalharem colorindo a letra do próprio nome usando as ferramentas do programa Kolorpaint, os alunos tiveram também que abrir a caixa de texto para digitar o próprio nome. Isso representou um novo desafio para essas crianças, que estavam acostumadas a desenvolver, em sala de aula, até então, apenas a atividade de colorir e registrar o nome de forma manuscrita em folha de papel, utilizando ferramentas próprias desse tipo de suporte, tais como: lápis, lápis de cor e borracha.

Pudemos perceber no trabalho final do aluno TA que, ao digitar o próprio nome, ele acrescentou letras e outros signos, numa forma de composição de seu nome. No período da pesquisa, ele ainda não dava conta de registrar todas as letras do próprio nome, e, ao indagarmos por que havia usado tantas letras e até o número três no próprio nome, ele nos disse que no teclado havia muitas letras e que, por isso, havia resolvido colocar "mais algumas". A professora F, no instante em que conversávamos com TA, comentou que o aluno não havia feito isso antes em sala de aula, isto é, misturar outros signos às letras do próprio nome. Com esse dado, refletimos melhor sobre o que representa um repertório pronto, ao alcance dos dedos, na escolha do recurso gráfico. Em outras palavras, essa possibilidade adotada pelo aluno surgiu a partir da experiência com o teclado do computador. Esse dado nos faz pensar na diferença que é representar a escrita na folha de papel, usando o lápis, e no computador, usando o teclado.

O fato de o computador exibir todas as letras, deixá-las expostas juntamente com outros signos, pode servir de elemento de distração para a criança, ou mesmo de experimentação quando esta tenta registrar a própria escrita pela primeira vez, pois no teclado há signos de sistemas ideográficos (números e sinais) e alfabéticos. Pode ser que isso não ocorra quando a criança escreve no papel, quando os signos não estão todos representados na folha para que ela faça a escolha de qual irá usar.

Outra análise que pode ser feita refere-se à característica multimodal dos textos que aparecem no computador, ou seja, vários são os modos pelos quais o texto se apresenta ao sujeito diante da tela. Afinal, escrever o nome no caderno é diferente de escrevê-lo na tela, uma vez que, neste último caso, a criança fica diante de um 
teclado repleto de caracteres e signos diferenciados. Assim, pode ser que ela não os conheça, mas tenha a curiosidade de conhecê-los e de usá-los, tudo isso, diante de uma tela brilhante em que aparece o texto digitado a cada vez que o sujeito tecla.

Segundo Kress (2009, citado por STREET, 2009, p. 19, tradução nossa), "as pessoas orquestram significado por meio de sua seleção e configuração dos modos [...] e as possibilidades são constantemente reformuladas ao longo das linhas das exigências sociais expressas em que se trabalha em busca do sentido". ${ }^{11}$

Acreditamos que a relação com a escrita se torna mais rica quando se aprende a lidar desde cedo com as possibilidades que cada um dos suportes de texto pode proporcionar àqueles que os experimentam. E isso significa, entre outros aspectos, reformular a escrita de acordo com seu suporte.

No caderno, para registrar o próprio nome, o aluno TA utilizou a memória e os conhecimentos sobre as letras que o compõem, mas, no teclado, experimentou novos caracteres e signos acoplados a seu nome. O simples fato de estar diante do teclado, com tantas opções de sinais gráficos, pode ter provocado a estratégia de mudar, acrescentar e fazer sua escrita de forma diferente.

Quando a isso, visando compreender, de um ponto de vista histórico, os indícios das práticas envolvidas na cultura escrita, Gómez (2003, p. 111) assim as define:

Las prácticas [...] sitúan el análisis de la cultura en el plano de los usos dados a la misma, de las competências efectivas del escribir y del leer, y de los modos de ponerlo en uso. Por un lado, aluden a las evidencias materiales de cada ejercicio de escritura y lectura; y por otro, señalan las condiciones en las que se hacen posibles.

A oportunidade de aprender a lidar com esse outro formato da escrita certamente traz efeitos sociais e culturais muito significativos para as crianças que estão na fase de alfabetização, em processo de incorporação das várias formas materiais e simbólicas de escrever e de ler textos em nossa sociedade, as quais se concretizam nos modos manuscritos, impressos e digitais.

\section{APRENDENDO GÊNEROS TEXTUAIS VIRTUAIS}

Iniciamos este tópico apresentando uma reflexão de Marcuschi (2003, p. 25, grifo do autor) que mostra a complexidade dos gêneros textuais:

Hoje, em plena fase da denominada cultura eletrônica, com o telefone, o gravador, 
o rádio, a TV e, particularmente o computador pessoal e sua aplicação mais notável, a internet, presenciamos uma explosão de novos gêneros e novas formas de comunicação, tanto na oralidade como na escrita. Isto é revelador do fato de que os gêneros textuais surgem, situam-se e integram-se funcionalmente nas culturas em que se desenvolvem. Caracterizam-se muito mais por suas funções comunicativas, cognitivas e institucionais do que por suas peculiaridades linguísticas e estruturais.

A partir da situação de uso do computador, a aprendizagem de novos gêneros textuais que surgem com esse novo suporte de texto ocorre integrada à cultura como forma de comunicação com o outro. Em relação às crianças, além de esse aprendizado poder ocorrer no meio familiar, quando a escola explora esse suporte e seu uso em pleno processo de alfabetização, podemos pensar em novos horizontes para o desenvolvimento da escrita. Segundo Vygotsky (1998, citado por RIBEIRO; ARAÚJO, 2007, p. 165), “o ensino deve ser organizado de forma que a leitura e a escrita se tornem necessárias às crianças [...]". No âmbito de nossa pesquisa as crianças que participaram da aula de e-mail puderam experimentar a escrita e a leitura de forma concreta como práticas sociais.

Planejar para crianças de 6 anos a atividade de enviar e receber e-mail pode parecer, a princípio, algo complicado e até difícil de se realizar para essa fase. Entretanto, com base em nossa pesquisa, pudemos perceber o quão significativo foi para essas crianças realizar tal tarefa.

Ribeiro e Araújo (2007, p. 165) comentam que

\begin{abstract}
Infelizmente, a experiência na escola tem mostrado que esse período de descoberta da leitura e da escrita parece ser substituído por uma gama de atividades e tarefas mecânicas, sem sentido para as crianças, e é exatamente nesta fase em que ouvimos dos professores e de alguns pais lamentações que já se tornam uma espécie de jargão: meu aluno (filho) não quer nada ou meu aluno(filho) não aprende nada. O que os pais e os professores precisam saber é que não pode haver aprendizagem onde não há sentido.
\end{abstract}

Concordamos plenamente com esses pesquisadores e constatamos em nossa pesquisa que, quando ocorrem situações de escrita autêntica ou de simulação de uso, as crianças apreendem o valor social do signo alfabético. Assim, a apropriação da escrita flui com mais facilidade, mesmo para aqueles que apresentam dificuldade em se alfabetizar.

Isso significa que, quando usamos gêneros textuais virtuais para trabalhar a escrita das crianças no início da alfabetização (como apresentaremos a seguir a partir da escrita do aluno TA), esse contexto pode ajudá-las a resolver determinadas questões de alfabetização. Isso ocorre porque elas empenham vários recursos para se comunicar com o outro no novo suporte de texto. 
Não queremos com isso dizer que o computador possua "uma varinha de condão" capaz de solucionar os problemas de alfabetização que afligem tanto a nós, professores, e é relevante lembrar que, durante a pesquisa, a professora F realizou um trabalho criterioso em sala de aula, em função da dificuldade de alguns em adquirir o sistema alfabético e desenvolver o uso da escrita. Destacamos apenas que esse suporte e seus gêneros possuem uma gama de recursos e ferramentas que chamam a atenção dos alfabetizandos, fazendo com que eles entendam e focalizem aspectos que antes não compreendiam e, até mesmo, que reflitam melhor sobre a escrita quando estão diante da tela.

Pesquisando crianças e seu contato com a escrita em suporte digital, Ribeiro $^{12}$ e Araújo (2007, p. 168) também afirmaram que:

As atividades vivenciadas durante a pesquisa demonstraram que as crianças, depois de compreender o sentido dos usos da escrita digital, passaram a escrever e a ler mais, sanando alguns problemas de leitura que haviam sido detectados antes do início da investigação.

A experimentação da escrita no suporte virtual de texto conta com multimodos: a tela apresenta brilho, movimento e imagem; o mouse e o teclado provocam novos gestos e comportamentos; e há ainda um conjunto de dados/repertórios disponíveis para escolha.

A seguir, analisamos uma das experiências por nós observadas de aprendizagem de gêneros textuais na esfera virtual, com a intenção de compreender suas implicações para a criança em fase inicial de alfabetização. A análise foi feita a partir da transcrição de alguns trechos de diálogo ocorrido no laboratório de informática. Além do resultado final da produção do e-mail, mostramos também o cartão de amizade feito em sala de aula pelo aluno citado na transcrição. Segue o trecho do diálogo:

$[\cdots]$

Pesquisadora: TA, esse espaço aqui é para mensagem.

Aluno TA: Como assim?

Pesquisadora: Escreva uma mensagem para o aluno AR.

Aluno TA: Que mensagem a gente escreve no e-mail?

Pesquisadora: No caso, como o assunto é AMIZADE, você vai escrever algo bonito para o aluno AR.

[Ele fica pensando]

Enquanto circulávamos na sala orientando outros alunos, TA produziu seu e-mail da seguinte forma: 
A Augusto Alves to me

show details 12/4/09

Forwarded message

From: T Andrade Lopes<t.horta.1@gmail.com>

Date: $2009 / 11 / 5$

Subject: amionho

To: a.horta.8@gmail.com

biutt. $\mathbf{T}^{13}$

T Andrade Lopes to me

O aluno TA ainda se apresentava silábico em sua escrita. Essas condições poderiam inibi-lo em sua escrita do e-mail, mas isso não ocorreu. Ao contrário, isso o estimulou a buscar mais conhecimento sobre a escrita. Primeiro, ele indagou o que seria mensagem de e-mail; depois, buscou uma forma de escrever. Como em nossa explicação sobre o que seria e-mail usamos a expressão "escrever algo bonito", e "bonito" é uma palavra que serve como mensagem, o aluno TA decidiu digitar a escrita dessa palavra, mesmo sem ter domínio da escrita alfabética. Isso é muito significativo, pois revela que a falta de domínio da escrita alfabética não impede o sujeito de tentar usar o gênero textual.

Araújo (2007) descreve experiência semelhante de produção de cartões digitais que foram trabalhados com crianças em processo de alfabetização e nos ajuda a reforçar a ideia de que a inserção da criança nos gêneros da esfera digital exige muitas habilidades inéditas ou bem específicas e que mesmo crianças consideradas em processo de exclusão, por ainda não terem aprendido a escrever com fluência, conseguem adquiri-las em processo de uso:

Nenhum cartão é feito sem que o remetente se submeta a um processo de escolhas através das quais ele gera a sua mensagem. Assim, a criança, imersa entre muitos cliques de mouse e digitações de caracteres, assume o seu papel de sujeito nessa nova experiência de escrita, experimentando o uso da língua a partir de uma situação de enunciação digital. Além de operar com o mouse e com o teclado, pondo o cursor no formulário certo antes de escrever o que lhe é solicitado, o pequeno escritor precisava equacionar as várias semioses que, inscritas na tela digital, conspiravam em favor do sentido que ele pretendia construir. (ARAUJO, 2007, p. 87)

Juntemos a essa análise a produção do cartão de amizade elaborado de forma manuscrita pelos alunos em sala de aula, no mesmo período em que experimentaram enviar e-mail. Para isso, 
eles receberam um papel dobrado em forma de um pequeno cartão, onde teriam que desenhar, colorir e escrever uma mensagem dedicada ao colega de turma como se fosse "amigo-oculto". A seguir, apresentamos o cartão produzido por TA:

FIGURA 2 - Cartão do aluno TA para 0 aluno AR

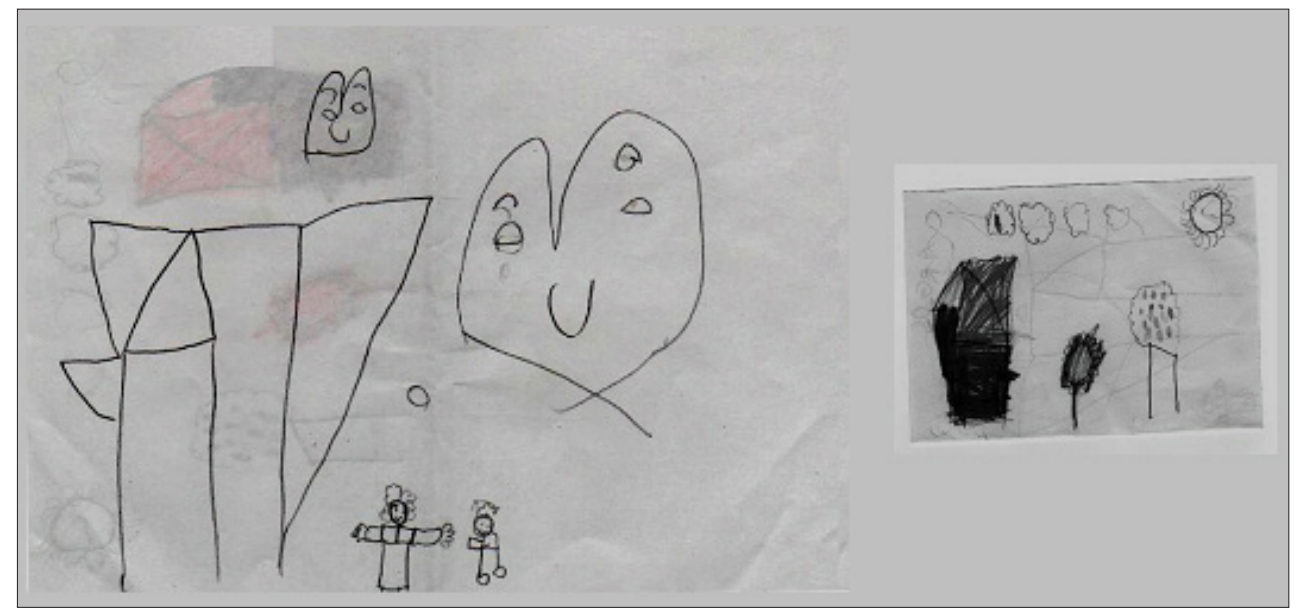

Fonte: Arquivo da professora F, 2009.

Verifica-se que, apesar de sua lentidão no processo de alfabetização, TA tenta, da mesma forma, comunicar-se com o outro. No cartão faz desenhos nos dois lados da folha dedicados ao amigo AR com muito carinho. No e-mail, tenta escrever a palavra "bonito"; afinal, dissemos a ele que tinha de escrever algo "bonito", conforme se pode verificar no trecho do diálogo no laboratório de informática já apresentado. Portanto, nem a falta de domínio da escrita alfabética nem o desafio de lidar com as formalidades do gênero digital de texto inibiram ou desmotivaram TA.

A esse respeito, Ribeiro e Araújo (2007, p. 167) comentam que:

Se de um lado, para alguns adultos, ainda é difícil adaptar-se às novas tecnologias, pois talvez em seu tempo de crianças ou mesmo de adolescentes não puderam vivenciar e experimentar a escrita digital, por outro lado, os jovens demonstram adaptar-se rapidamente a essas tecnologias, pois navegam pelas ondas da Internet sem grandes dificuldades, comunicando-se com muitos amigos através de muitos gêneros digitais [...].

Podemos notar que, ao experimentar a produção do cartão de papel, TA desenha, mas não tenta escrever mensagem; a única escrita que ele realiza é a do nome do colega (colocado devidamente se levarmos em conta a estrutura do cartão) para quem dedica o cartão. 
De outra forma, no e-mail, TA preocupa-se em escrever (quer saber o que se escreve nesse gênero virtual de texto). Ele utiliza a escrita alfabética em várias situações: digita o endereço eletrônico do colega (mesmo que tenha sido uma cópia da lista de e-mails preparada pela professora); digita o assunto estabelecido com a turma ("amionho" = "amizade") e digita a mensagem ("biutt" = "bonito"). Além de digitar, ele ainda teve que descobrir como preencher o formulário de apresentação do e-mail. Em todas essas tarefas envolvendo a escrita, TA mostrou-se muito interessado.

Não queremos dizer com isso que, em relação ao cartão manuscrito, TA demonstrou desinteresse. O fato é que, diante do espaço virtual, ele apresentou mais resultados em termos de escrita aproveitando o teclado, em que os signos alfabéticos estão todos dispostos para se escolher, e usando-o juntamente com o mouse.

$\mathrm{O}$ que se pôde constatar foi que, independentemente de seu domínio do registro escrito, diante da tela, TA digitou o e-mail. Em outras situações de escrita e de leitura no computador, ele sempre procurou desenvolver as tarefas com muita dedicação, a ponto de a própria professora da turma chegar à conclusão de que as aulas no laboratório de informática estavam sendo fundamentais para seu aprendizado da escrita.

Observando a vivência de TA com o novo suporte de texto, percebemos que sua postura teve que mudar, e isso foi muito construtivo no processo de aprendizagem de todos, ocorrendo até mesmo certa melhora na concentração quando a atividade (no computador) era feita individualmente (concentração que em sala de aula não acontecia em atividades individuais e tampouco em grupo). Nesse sentido, entendemos que as contribuições do uso do computador tendem a ser cada vez mais efetivas à medida que as crianças tiverem oportunidades diversas de experimentar a escrita nesse suporte e em várias situações comunicacionais.

\section{CONCLUSÃO}

Ao ponderar sobre investigações que levem em conta instrumentos e suportes para ler e escrever na escola, Frade (2009, p. 41) afirma que "do ponto de vista histórico precisamos de novas pesquisas para investigar que lugar ocupam determinados suportes em cada nível de ensino, para qual tipo de atividade estes são empregados". A mesma autora interroga sobre os efeitos da materialidade nas práticas de escrita. Os estudos sobre a história do livro e da leitura, sobretudo os de Roger Chartier, ajudam-nos a compreender os principais efeitos da materialidade na produção e na 
recepção dos impressos ou dos manuscritos, mostrando a diferença entre eles e as continuidades entre a cultura manuscrita e a impressa, o que nos ajuda a pensar permanências e continuidades na produção e na recepção dos escritos. Os estudos sobre a cultura escrita também revelam o peso da materialidade de livros, suportes e instrumentos nas práticas de escrita, pois esses aspectos são primordiais para entender "as circunstâncias que intervêm no momento de criar ou fabricar um produto da cultura escrita" (GÓMEZ, 2003, p. 105). Assim, a pesquisa sobre práticas contemporâneas e usos sociais da escrita, ou seja, estudos sobre o letramento que envolvem novos suportes, encontram maior sentido se contemplarmos as práticas do presente pensando nas continuidades da cultura escrita ou também nos gestos e nos comportamentos inéditos que a cultura digital propicia.

Os dados põem em evidência o fato de que, mesmo quando não trabalhamos atividades com gêneros textuais virtuais, repetindo práticas escolares semelhantes às que desenvolvemos com a escrita manuscrita, notamos que as ferramentas digitais transformam e dão uma nova roupagem à tarefa, ou melhor, aparecem novos aspectos cognitivos e físicos relacionados ao ato de escrever e ler. Com isso, os alunos, muitas vezes, voltam sua atenção para estruturas da escrita ou para aspectos gráficos não percebidos quando operavam com outro formato e outro suporte de texto. Desenvolvendo atividades de produção e leitura de texto no espaço digital, a criança tem a oportunidade de aprimorar sua escrita dentro dos espaços virtuais, utilizando novos gêneros textuais, desenvolvendo novos letramentos (SOARES, 2002; STREET, 2009) e compreendendo a dimensão comunicacional, cultural e social da escrita.

Por meio do desenvolvimento de aulas que tomam como suporte o computador, a produção escrita e os gêneros existentes nesse espaço, constatamos que o ensino da língua para as crianças desta pesquisa teve um significado especial; elas aprenderam a escrever para se comunicar por meio dos gêneros textuais, incluindo os da mídia virtual. Dessa forma, ressaltamos que trazer para a escola variedades tanto de suportes como de gêneros que circulam socialmente sempre causa efeitos benéficos, não só para a aprendizagem de conhecimentos formais como também para a vivência de práticas sociocomunicativas que envolvem os textos.

Em síntese, percebemos que a presença do computador é benéfica no período de alfabetização, como mais um suporte para a criança ler e escrever na escola, entre tantos materiais que compõem a cultura de escrita escolar. Dessa forma, a ausência do computador numa alfabetização contemporânea pode empobrecer as experiências vivenciadas pelas crianças, tendo em vista que seu uso já faz parte da cultura escrita. 


\section{REFERÊNCIAS}

ARAUJO, J. C. Os gêneros digitais e o desafio de alfabetizar letrando. Trab. Lin. Aplic, Campinas, 46 (1) p. 79-92, jan./jun. 2007. Disponível em: <http://revistas.iel.unicamp.br/ index.php/tla/article/viewFile/1851/1446>. Acesso em: 21 set. 2010.

CHARTIER, R. A aventura do livro: do leitor ao navegador. Editora UNESP, São Paulo. 1997. Os desafios da escrita. Tradução de Fulvia M. L. Moretto. São Paulo: UNESP, 2002.

Práticas de leitura e escrita: história e atualidade. Belo Horizonte: Autêntica. 2007.

CHARTIER, A. M. Qual o papel da cópia na alfabetização? Jornal Letra A, Belo Horizonte, 3. Maio/jun. 2008. Caderno Troca de ideias, p. 8.

FERREIRO, E.; TEBEROSKY, A. Psicogênese da língua escrita. Porto Alegre: Artes Médicas, 1985.

FRADE, I. C. A. Suportes, instrumentos e textos de alunos e professores em Minas Gerais: indicações sobre usos da cultura escrita nas escolas no final do século XIX e início do século XX. História da Educação, São Paulo, ASPHE, FAE, UFPel, p. 29-55, set./dez. 2009.

GOMEZ A. C.. Historia de la cultura escrita. Ideas para el debate. Revista Brasileira de História da Educação, São Paulo, n. 5, p. 93-124, jan./jul. 2003.

LERNER, D. Qual o papel da cópia na alfabetização? Jornal Letra A. Belo Horizonte, 3. Maio/jun. 2008. Caderno Troca de ideias, p. 8

MARCUSCHI, L. A. A questão do suporte dos gêneros textuais. DLCV: Língua, Linguística e Literatura, João Pessoa, v. 1, n. 1, p. 9-40, 2003. Disponível em: <www.sme.pmmc.com.br/ arquivos/matrizes/ matrizes_portugues/anexos/texto-15.pdf> Acesso em: 17 set. 2009.

MOLINARI, M. C.; FERREIRO, E. Identidades y diferencias en las primeras etapas del proceso de alfabetización. Escrituras realizadas em papel y en computadora. Lectura y vida, Argentina, v. 28, n. 4, p.18-30, 2007.

RIBEIRO, M. M.; ARAÚJO, J. C. “Tia, eu já escrevi o site do 'Rotimeio’. Agora é só Apertar o Enter?” O Endereço Eletrônico na Sala de Aula. In: ARAÚJO, J. C. (Org.). Internet \& ensino: novos gêneros, outros desafios. Rio de Janeiro: Lucerna, 2007.p. 165-178.

SOARES, M. Novas práticas de leitura e escrita: letramento na cibercultura. Educação e Sociedade, São Paulo, v. 23, n. 81, p. 143-162, dez. 2002.

STREET, B. Multimodality and New Literacy Studies’ Festschrift for Gunther Kress, 2009. Inédito.

STREET, B. Multimodalidade. In: FRADE, I. C. A. S; VAL, M. da G. C. G; BREGUNCI, M. das G. C. Glossário Ceale de termos de Alfabetização, leitura e escrita par educadores. Belo Horizonte, CEALE/Faculdade de Educação da UFMG. 2014. p. 229-231. Disponível em: <ceale.fae. ufmg.br/app/webroot/glossárioceale/verbetes/multimodalidade >. Acesso em: 18 jun. 2010.

\section{NOTAS}

${ }^{1}$ Para preservar o anonimato dos alunos citados, utilizamos letras no lugar do nome de cada um deles, tanto nas transcrições como nas análises.

${ }^{2} \mathrm{~A}$ respeito do conceito de multimodalidade, que não se refere apenas às linguagens presentes no mundo digital, Brian Street (2014, p. 229-230) considera que "o ensino e a aprendizagem da leitura e da escrita precisam levar em conta, atualmente, a variedade dos modos de comunicação existentes, o que chamamos de multimodalidade. Nessa nova perspectiva, que se opõe às abordagens educacionais ocidentais mais tradicionais, devem-se considerar os modos de comunicação linguísticos - a escrita e a oralidade -, visuais - imagens, fotografias -, 
ou gestuais - apontar o dedo, balançar a cabeça negativa ou afirmativamente, por exemplo. Essa diversidade de modos de comunicação foi incorporada tanto pelos meios de comunicação mais tradicionais, como livros e jornais, quanto pelos mais modernos, como computadores, celulares, televisão, entre outros".

${ }^{3}$ Para manter o anonimato dos envolvidos na pesquisa, utilizamos a letra $\mathrm{F}$ no lugar do nome da professora da turma.

${ }^{4}$ Esta pesquisa se desenvolveu em nosso doutorado pelo programa de Pós-Graduação da FAE/UFMG, contou com a participação da professora alfabetizadora de escola pública municipal em $\mathrm{BH}$ que lecionava em turma do primeiro ano do ciclo de alfabetização. Professora, pesquisadora e orientadora formaram uma equipe para a elaboração das atividades de alfabetização planejadas para o suporte digital e para análise e reflexão sobre os eventos observados, filmados e registrados em caderno de campo, logo após cada evento de intervenção. ${ }^{5}$ Nota registrada em caderno de campo após conversa informal com a professora F.

${ }^{6}$ Denominamos contato pessoal ou direto com o computador aquela vivência em que a criança tem a oportunidade individual de manipular a máquina, seja para jogar, para desenhar, escrever ou ler textos.

${ }^{7}$ Não há como isolar a cultura digital vivenciada num computador de outros contatos como celular, jogos, caixas de supermercados, entre várias outras experiências, mas nesse caso estamos nos referindo ao uso da máquina e de alguns de seus programas.

${ }^{8}$ Observamos que, devido à rapidez de mudanças, uma das principais características do mundo tecnológico, essa rede social já foi extinta na atualidade.

9 "Baldinho" é uma das ferramentas usadas no Kolorpaint para colorir.

${ }^{10}$ Professora coordenadora do laboratório de informática.

11 "People orchestrate meaning through their selection and configuration of modes [...] and affordances are constantly reshaped along the lines of the social requirements expressed in that work by those making meaning".

${ }^{12}$ Ribeiro, orientada por Araújo, desenvolveu uma pesquisa-ação com alunos em processo de alfabetização.

${ }^{13}$ Essa foi a produção escrita do aluno TA em que pretendeu escrever a seguinte mensagem: "bonito".

Recebido: 10/12/2013

Aprovado: 11/05/2015

Contato:

Julianna Silva Glória

Rua Maria Amélia Maia, 455, B. São Bernardo

Belo Horizonte $|\mathrm{MG}|$ Brasil

CEP 31.741-308 